\title{
Problems and Suggestions for the Scientific Research Management System of Universities
}

\author{
Liang Zhao* \\ Institute of Scientific Research and Development, Chongqing University, Chongqing 400044, China \\ *Corresponding author: Liang Zhao, 446399143@qq.com
}

\begin{abstract}
The revolution of science and technology in the new era is rising. New industries, formats, and models led by information technology are emerging. Scientific research has entered the fourth data-intensive paradigm. As an important part of the science and technology innovation system, universities also have new requirements for their scientific research management system. In this article, it is suggested that the efficiency and quality of scientific research management in universities could be enhanced by reconstructing the organizational structure of scientific research management, improve the service capabilities of scientific research managers, perfecting the scientific research evaluation system, and innovating the management model of cross-research teams.
\end{abstract}

Keywords: Scientific research management; Organizational structure; Institutional innovation; Scientific research paradigm

Publication date: June 2021; Online publication: June 30, 2021

\section{Introduction}

The innovation of science and technology is an inexhaustible driving force for development. As an important part of the national science and technology innovation system, universities have made outstanding contributions to the national rejuvenation via strategic implementation of science and technology in education. The world today is experiencing great changes that have not been seen in centuries. With the continuous acceleration of economic globalization, scientific and technological innovation skills have become the indicators of a country's core competence in the support of social and economic development which are related to the nation's prosperity and development. In recent years, China have been enhancing their governance and raising investments to expand scientific research on universities while proposing the construction of world-class universities and first-class disciplines. Hence, in the construction of universities' scientific research management and their teams, there is a need for constant improvement, revision, optimization, and innovation in terms of their concepts, service modes, and management systems to ensure that the research management system meets the requirements of the development of universities in the new era.

\section{Basic organizational structure of the scientific research management system of universities}

At present, the scientific research management of China's universities is a three-level management model which is composed of universities, schools, and research teams. According to the classification of organizational structure based on organizational behavior, the Scientific Research Office (Institute of Science and Technology) on behalf of universities, exercises the function of the scientific research management. It comprises of the General Office, Project Office, Achievement Office, etc. and each of these offices has its own unique function in which it resembles a typical organizational structure. ${ }^{[1]}$ In the academic field, universities have established different schools such as School of Materials, School of 
Mechanical Engineering, School of Computer, and School of Medicine. Each school has their own independent administration, research, and teaching system; bearing resemblance to the multidivisional structure model.

For each research team in the university, the school is responsible for the related teaching work of its researchers, the team is responsible for the research tasks, and the financial department is responsible for the research funds. The researchers in the same research team may come from different colleges and their organizational structure is a typical matrix structure.

\section{Problems existing in the scientific research management system of universities}

The three-level management model comprising of universities, schools, and research teams is a mixed structure from a micro point of view. There are many problems in the actual management process due to the management inertia of functional departments, the characteristics of each school, the number of research team members, and other factors.

\subsection{Prominent administrative behavior of the scientific research management}

Due to the administrative management of scientific research, functional departments and scientific research units in universities represent a dual structure. ${ }^{[2]}$ Scientific research managers focus on functional needs, work according to instructions from their superiors and emphasize standardization in the work process while neglecting the freedom and unpredictability of scientific research and its creation process which is caused by the inertia of the organizational system in China's universities.

At the same time, the design of the scientific research management system mainly involves scientific research agencies, schools, and the head of relevant departments. Ordinary researchers are rarely involved in decision-makings and the arrangements of the system. The excessive participation of administrative power leads to a deviation between the system's design and the law of scientific research activities. In addition to that, it directly affects the efficiency of scientific research management and causes friction between research managers and researchers.

\subsection{Lack of effectiveness among scientific research management departments}

Although there are many functional departments in local universities, the allocation of scientific research management personnel is relatively tight and many scientific research teams do not have full-time management personnel. For example, in a university with nearly 5,000 scientific researchers, there are only over 30 people in the scientific research management department. In addition, administrative affairs are complicated and the workload is overwhelming. The functional departments have to face various trivial affairs on a daily basis which makes it difficult to meet the needs of scientific research personnel. Firstclass universities in the United States have the ratio of administrators to faculty close to 3:1 which lays the foundation for efficient and high-quality scientific research work. ${ }^{[3]}$

\subsection{Failure of the research management model in adapting to the scientific research paradigm shift}

The paradigm was introduced by Thomas Kuhn, a famous American philosopher and was systematically expounded in "The Structure of Scientific Revolution." The scientific research work paradigm is the recognized scientific research organization mode, way, or routine which guides and leads scientific research work. ${ }^{[4]}$

Due to the brief development history of China's higher education, the introduction and imitation model, task-led discipline model, basic theory to applied research model, discipline-led task model, problem-driven model, and demand-oriented model have been applied to the organization model of scientific research. The 
evolution of these models is in relation to China's national situations and development. ${ }^{[5]}$ At present, the scientific research management mode in universities is divided according to discipline fields. This forms a scientific research organization management mode that carries out research tasks in a particular discipline and promotes the development of disciplines via research. Limitations of these discipline fields are obvious and they are not in line with the current characteristics of data-intensive scientific research paradigm based on big data.

\subsection{Imperfect scientific research evaluation system}

Scientific research evaluation is an important aspect of scientific management in universities. In the initial stage of scientific research development in China, in order to reduce the influence of the experts' personal factors on scientific research evaluation, a single quantitative index was established in various scientific research evaluations which had a positive impact at that time. With the development of society and the continuous advancement of science and technology management in universities, this single evaluation system results in a situation whereby researchers and research units would carry out scientific research work only for the sake of papers, hats, titles, and awards which to a certain extent, negatively impact the ecology of scientific research in universities and the development of scientific research. At the same time, this quantitative evaluation method cannot fully and truly reflect the quality, effectiveness, characteristics, and contributions of scientific research to the society.

\section{Suggestions for the construction of scientific research management innovation system}

\subsection{Strengthening the construction of professional scientific research management teams and enhancing their scientific research service capabilities}

The main body of scientific research management should be management personnel with excellent comprehensive quality, strong innovative skills and team awareness, familiar with businesses, and are good in coordinating the management. Scientific research management teams should strengthen their service consciousness, organizational planning, cooperation, communication, and their comprehensive service capabilities. Only an efficient and systematic management would be able to make the most out of the limited resources inside and outside universities as well as achieve the expected management goals.

At the same time, with the improvement and standardization of research information management and services in developing the "one-stop" scientific research online service for project management as well as realizing the functions of project declarations, approvals, process managements, delivery, reimbursement, fund claims and uses, etc., these would allow more data to run while educators do not need to worry about these cumbersome issues, hence, improving the overall scientific research operation efficiency.

\subsection{Optimizing the structure of scientific research management system}

In the management of scientific research in universities, the status of "research" should be highlighted. Therefore, in the division of labor and coordination of scientific research organization system, scientific research units especially the project teams should be placed in the core position.

In the existing scientific research management organization system, there is no particular position for the project teams which is also the reason why many project teams have difficulties in carrying out their work. Project teams should be placed at the core position while colleges provide a platform for research work and universities allocate resources for these colleges and their project teams. Work functions can then be carried out around the project team, thus reducing the transactional work pressure related to communication and coordination, financial reimbursement, data management, etc. so that researchers can devote their energy to research. 
Therefore, it is recommended to design a scientific research organization system with the idea that "the core is the project team, platforms are provided by colleges and departments, and resources are allocated by universities."

\subsection{Further improving the scientific research evaluation system}

Universities should gradually implement long-term research evaluation mechanisms, construct and improve the multiple evaluation systems of scientific research activities, formulate classified and multi-level assessment methods, outline various assessment standards for different fields and disciplines, promote the research field, industrial technology, social, and economic development, understand the potential social effects, conduct personnel trainings, as well as improve other dimensions of comprehensive evaluations. Basic evaluation methods that combine quantitative and qualitative evaluations should be adhered to and third-party evaluations should also be gradually improved to ensure fair, scientific, and reasonable evaluations.

\subsection{Exploring the establishment of an interdisciplinary innovation mechanism}

Interdisciplinarity is the only way to improve scientific and technological innovation skills. Universities have the advantage of interdisciplinary research and development (R\&D). Universities should then explore the innovative mechanisms of interdisciplinary communication and cooperation, establish new interdisciplinary R\&D institutions, strengthen docking with enterprises, and initiate interdisciplinary integration projects based on demands. Universities should also play a role in guiding scientific researchers to form interdisciplinary teams, developing new talent flow mechanisms, establishing stable and creative cooperation modes for independent innovations in science and technology, carrying out interdisciplinary research, and gradually establishing various interdisciplinary research centers in line with the construction of R\&D teams.

\section{Conclusion}

In short, China's scientific research in universities is currently facing challenges as well as opportunities such as the transformation of scientific research paradigm and adjustments of the scientific research evaluation system.

For universities, in order to establish a scientific research management system compatible with the national innovation system, it is necessary to innovatively tune the organizational structure and the management system, create a favorable environment for scientific research, as well as establish management mechanisms with incentive effects and people-oriented in order to stimulate the scientific research vitality and enthusiasm of scientific researchers to the maximum extent. In this way, scientific research would be able to promote high-quality development of universities, thus contributing much more to the economic and social development.

\section{Disclosure statement}

The author declares no conflict of interest. 


\section{References}

[1] Robbins SP, Judge TA, 2016, Organizational behavior [Sun JM, Wang Z, Li Y, etc., Trans.], China Renmin University Press, Beijing.

[2] Campbell, 1989, Modern American higher education [Yuan R, Trans.], Guangdong Higher Education Press, Guangzhou.

[3] Lu CH, 2010, The enlightenment of American advanced scientific research management. Science Technology and Life, (22): 161.

[4] Hey T, Tansley S, Tolle K, 2009, The fourth paradigm, Microsoft Press, Washington D. C.

[5] Wang ZD, Du P, 2019, The formation, development, and prospect of the discipline system since the founding of New China. Science and Technology Review, 37(18): 60-9. 